\title{
Fluctuations in Human Bioenergy during the Day as Observed from the Evoked Photon
}

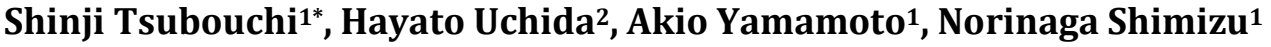 \\ ${ }^{1}$ Division of Health Science, Faculty of Liberal Arts and Sciences, Osaka Prefecture University, Osaka, Japan \\ ${ }^{2}$ School of Human Science and Environment, University of Hyogo, Hyogo, Japan \\ Email: *tsubouti@las.osakafu-u.ac.jp
}

How to cite this paper: Tsubouchi, S., Uchida, H., Yamamoto, A. and Shimizu, N. (2018) Fluctuations in Human Bioenergy during the Day as Observed from the Evoked Photon. Health, 10, 1309-1320. https://doi.org/10.4236/health.2018.1010101

Received: September 7, 2018

Accepted: October 14, 2018

Published: October 18, 2018

Copyright (c) 2018 by authors and Scientific Research Publishing Inc. This work is licensed under the Creative Commons Attribution International License (CC BY 4.0).

http://creativecommons.org/licenses/by/4.0/

(c) (i) Open Access

\begin{abstract}
Background: Measurement of the evoked photon is newly introduced method for measuring life activities those amplify weak light emitted from organisms. We examined the relationship of bioenergy fluctuation state in vivo with conventional physical parameters during twelve hours of daytime arousal using evoked photon measurements. Evaluation of metabolic level, one of the bioenergy state, has demonstrated its effectiveness by evoked photon. Methods: The evoked photon, a weak light emitted from organisms, is a new parameter for measuring life activities, which was recorded using gas discharge visualization (GDV) equipment, and the area and intensity of the energy field index from the GDV image glow were correlated to biorhythmic fluctuations, as corroborated by biochemical measurements of secretory-immunoglobulin A (s-IgA) levels. Result: The area and intensity of the energy field index at the time of awakening were significantly lower $(p<0.05)$ than the values obtained after being awake for $12 \mathrm{~h}$. Conclusions: Thus, the evoked photon reflects the bioenergy of the entire body and can be used as a general indicator of physical health.
\end{abstract}

\section{Keywords}

Biophoton, Daily Fluctuations, GDV, In Vivo Energy, s-IgA

\section{Introduction}

Before the establishment of modern medicine, the fact that the human body exhibits rhythmicity was well known, and the study of in vivo rhythms has been of ongoing interest in the medical community. The rhythms of the heart rate and breathing are known as immediate bodily activities. Fluctuations in physical functions associated with seasonal cycles were recorded by Hippocrates [1]. 
In 1729, Mairan [2] detected that the nyctinastic movement of Mimosa pudica leaves continued regularly, even in a dark environment, leading to the discovery of the endogenous biorhythm. Richter confirmed the endogenous rhythm through animal testing in 1926 [3]. Subsequently, Kleitman confirmed this rhythm by employing humans as experimental subjects in 1939 [4].

After it was established that the circadian rhythm was endogenous, Moore [5] and Stephan [6] detected the mammalian biological clock in the suprachiasmatic nucleus of the brain, leading to the full-scale development of the science of biorhythm in 1972.

Living organisms emit extremely weak electromagnetic waves (photons) during their daily living activities. Extremely weak photons were recently identified and termed "biophotons," combining the term "bio," meaning life, and "photon," meaning quantum of light. This recent finding established the new concept of "biological light" and can provide useful information.

Evoked photons have attracted much attention as an important indicator of life. They are caused mainly by reactive oxygen and free radicals produced from the chemical excitation of biological substances in in vivo oxidative metabolic processes. Thus, this light-emitting behavior has been universally observed in conjunction with activities and physiological metabolism [7].

Gas discharge visualization (GDV) is a quantum physical verification method that observes biophoton variations by analyzing the living body's electron movements. Even in inanimate objects, an increase in excited electrons indicates that the energy state has increased. For in vivo energy activity indicated by the evoked photon, the GVD characteristics need to be understood [8].

In living bodies, these electron movements are the "excited electrons" delocalized in the conjugated protein molecules in the epidermis and hypodermis. This light emission has been reported to be related to the electrons in an excited state in the living body [9] [10]. The GDV technology causes inanimate objects and living bodies to emit light from such electrons as strong electromagnetic fields for evaluating the electrons' energy level. Electrons are accelerated several thousand times to release spontaneous emission, and the luminescence phenomenon due to the combination of particles is captured with a charge-coupled device (CCD) camera.

Technologies that can minimize the influence of high-voltage equipment have been used to develop a GDV device that is highly reproducible and can minimize noise [11] [12] [13] [14]. Konstantin Korotkov (Saint Petersburg State University, Saint Petersburg, Russia) caused the induction of electrons from the skin using an electromagnetic field based on the Kirlian effect. A powerful feature of GDV is the use of arithmetic means of repeated recordings of the glow image areas of all fingers in order to reliably detect stress reactions to at least certain types of external stressors [15] [16]. These excited electrons are closely related to adenosine triphosphate and active oxygen, which are the basis of in vivo energy. Thus, the complete psychological and biological state can be evaluated through 
GDV measurements, and this can be regarded as a holistic health index for the body. By utilizing the "area" and "intensity" as basic evaluation indices, a complete interpretation of the mental and physical states needs to be correlated with the external environment. The area and the intensity can be interpreted as physically related to photon energy, and they are defined as reserve energy or converted to retained energy. The area and the intensity are also usually proportional to the normal functioning levels of the mind and body. Therefore, when a person experiences restful sleep, the level of the induced photons rises and both the light-emitting area and emission intensity increase. Based on improvements in the energy state of the body, it became possible to physically quantify the entire mental and physical conditions of the entire body.

By applying computer image analysis, the GDV device converts digital photographs of electrophotonic glow into several expedient parameters on the basis of the sizes and distributions of the flashes recorded. The GDV technique can be used to safely obtain electrophotonic Kirlian emission data; the reproducibility issues related to this method have been described extensively in the literature [11] [12] [13] [17] [18] [19] [20].

Inspection using the evoked photons is noninvasive. Evoked biophotons can be measured quickly and unobtrusively. Considering the large volume of physiological information that is included in the emission area and the light emission intensity of the photons, to utilize evoked photons has a very high potential for applications as a first measurement method for biological and mental health information.

Research on evoked photons using GDV has primarily been conducted in the United States and Russia, and numerous reports have been submitted to the Applied Physics Society and others [21] [22] [23]. Currently, especially in European and American medical facilities, the use of GDV and evoked photons is spreading for diagnostic purposes. In Japan, only a few studies on evoked photons to biological energies have been published [8], with very few studies being conducted on Japanese subjects.

\section{Purpose}

In this study, our objective was to examine the daily fluctuations of the evoked photon parameter indicators and how these reflect the diurnal variation of in vivo metabolic energy.

\section{Methods}

\subsection{Experimental Subjects}

Subjects were 25 adult men who were evaluated as medically healthy and were within the standard range of the same age for Japanese [24]. Their Physical characteristics were shown in Table 1.

After the aims of this study were explained to the participants in detail, they provided informed consent for living body load examinations. This study was 
approved by the Ethics Committee of the Faculty of Liberal Arts and Sciences of Osaka Prefecture University.

\subsection{Data Acquisition for the Verification Items}

In order to capture the daily evoked photon fluctuations of the subjects, examinations were conducted seven times a day (at 9:00, 11:00, 13:00, 15:00, 17:00, 19:00, and 21:00). The subjects spent most of their time at a desk and were not permitted to partake in any intense physical activity. The examination procedure involved acquiring the following data: secretory-immunoglobulin A (s-IgA)/total protein ratio, electrocardiogram data, oxygen intake data, calorie consumption data, and biophoton measurements.

The evoked photons were measured using a GDV device, Impulse Analyzer EPA (GDV) Compact (manufactured by Kirlionics Technologies International, St. Peterburg, Russia) bioelectrography device [25]. A GDV camera was connected to a computer, and the recorded glow image was digitally transformed using GDV capture software (version 1.9.9.2004). The GDV Analysis and Diagram software packages (both version 1.9.9), as well as the GDV Scientific Laboratory software (version 1.1.5), were used for further calculations and analyses.

During the examination, the subject's fingers were placed on the lens of the GDV device and the images were captured in a specified order (Figure 1). The

Table 1. Physical characteristics of subjects.

\begin{tabular}{ccccc}
\hline $\mathrm{n}=25$ & Age (years) & Height $(\mathrm{cm})$ & Weight $(\mathrm{kg})$ & BMI $\left(\mathrm{kg} / \mathrm{m}^{2}\right)$ \\
\hline Mean & 22.2 & 171.0 & 62.9 & 21.4 \\
SD & 1.3 & 6.2 & 10.0 & 2.8 \\
\hline
\end{tabular}

\section{(1)}

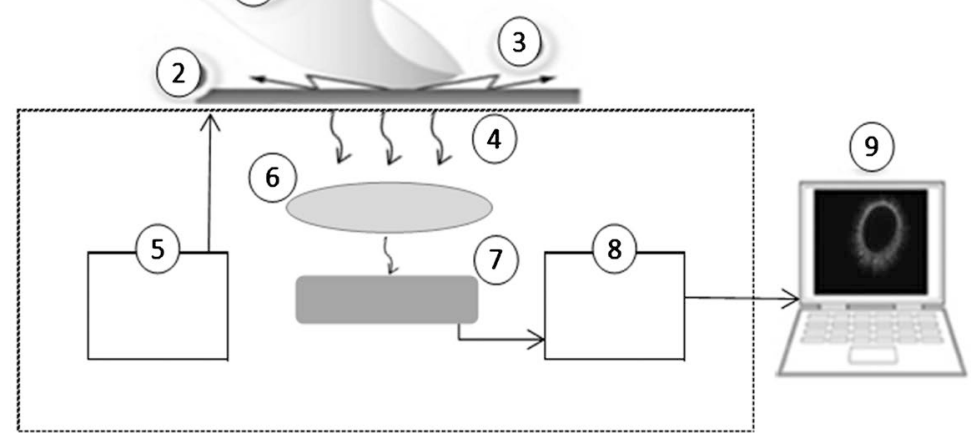

Figure 1. Flow of Measurement Analysis by GDV. Place naturally on the lens and keep the angle of the finger and lens between $15^{\circ}$ and $40^{\circ}$. The finger (1) is placed on the GDV lens (2), and the electromagnetic field is generated on the GDV lens by the booster (5). Gas discharge (gas discharge between the finger and the lens) (3) arises by the generation of the electromagnetic field due to electrons in the skin of the finger. At that time, the resulting light emission (4) is photographed by the CCD camera (6), sent to the optical system (7), the photographed content is digitized by the video converter (8) and sent to the computer (9). 
angle between the fingers and the lens was maintained at $15^{\circ}-40^{\circ}$ (Figure 1).

The s-IgA/protein ratio was measured by directly collecting a saliva sample from the mouth into a $50 \mathrm{~mL}$ centrifuge tube.

The measured electrocardiogram and oxygen intake data were analyzed using a gas analyzer (IX-TA-220, Epson Seiko, Tokyo, Japan) manufactured by iWorx. The daily heart rate was recorded using a GPS sports monitor (WristableGPS SF-810, Epson Seiko, Tokyo, Japan).

\subsection{Analysis Method}

Evoked photon parameters were applied to the GDV Meridian Analysis and Diagram software (version 1.9.9) and GDV Scientific Laboratory software (version 1.1.5). All GDV programs were developed by Konstantin Korotkov (Saint Petersburg State University). The value of area and intensity was calculated as the energy field index of the evoked photon parameter.

"Area" refers to the area of light emission, so the in vivo energy is high when this value is high. "Intensity" refers to the intensity of light emitted, so the in vivo energy and neural transmission ability are high when this value is high.

For analysis of s-IgA protein ratio, saliva was collected in conical tubes, frozen, thawed, transferred to a $1.5 \mathrm{ml}$ micro tube, centrifuged at $15,000 \mathrm{rpm}$ for 5 minutes, and the obtained supernatant was used as a material. The s-IgA/protein ratio was calculated by measuring the immune protein content using a sandwich enzyme immunoassay and by measuring the concentration of protein in the saliva using the Lowry method [26] [27] [28] [29]:

$s-I g A /$ protein ratio in the saliva $=(s-I g A$ concentration $) /($ total protein concentration $)$.

If the s-IgA/protein ratio is high, the subject will show high stress resistance.

The heart rate was calculated from the electrocardiogram using the GPS sports monitor's Neo Run function for data processing. Calorie consumption was calculated from the relational formula between the heart rate and oxygen intake using the continuous heart rate recording method [30] [31].

\subsection{Biomedical Statistics}

All experimental data were compiled into Microsoft Excel 2016 (Microsoft Corp., Redmond, WA, USA). For statistical analysis of daily fluctuations of the energy field parameters, one-way analysis of variance (ANOVA) was utilized. Tukey's honestly significant difference test was used for multiple comparison assessments. Correlation coefficients were obtained using a t-test. The level of statistical significance in this study was set at $5 \%$.

\section{Results}

\subsection{Level of Daily Activities}

The average heart rate and daily calorie consumption of the awake subjects were $75.8 \pm 9.2$ beats $/ \mathrm{min}$ and $936.4 \pm 87.6 \mathrm{kcal}$, respectively. The subjects were within the standard deviation of the average Japanese person [24]. The heart rate varia- 
bility of Subj. S.N. is shown in Figure 2 as the representative value of subjects.

\subsection{Daily Evoked Photon Fluctuations for Awake Subjects}

The evoked photon energy field parameters of area and intensity were analyzed. The area fluctuated throughout the measurement timeframe in a cyclic up and down fashion: $12,311 \pm 1406$ pixels at 9:00; $12,585 \pm 1916$ pixels at 11:00; 12,177 \pm 1365 pixels at $13: 00 ; 12,563 \pm 1136$ pixels at $15: 00 ; 11,852 \pm 1525$ pixels at 17:00; $12,087 \pm 1516$ pixels at 19:00; and 11,873 \pm 1207 pixels at 21:00 (Figure 3). A significant decrease was observed at 21:00 compared to the starting value at 9:00 ( $\mathrm{p}<0.01)$. This revealed that the daily fluctuations of area had three local maximum points. The energy indicator area of the evoked photon parameter revealed fluctuations in in vivo energy during normal waking hours. The intensity also fluctuated throughout the measurement timeframe in a cyclic up and down fashion: $83.2 \pm 2.3$ units at 9:00, $84.5 \pm 1.9$ units at 11:00, $83.5 \pm 2.5$

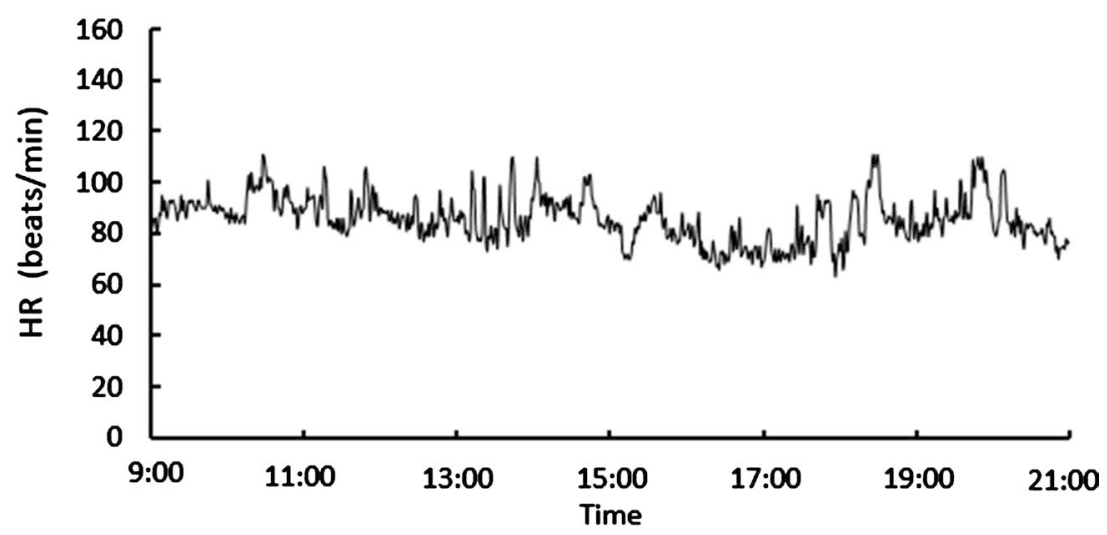

Figure 2. Level of daily activities. The subjects' S.N. showed fluctuations in arousal heart rate from 9:00 to 21:00. The average heart rate was $85.9 \pm 9.44$ (beats $/ \mathrm{min}$ ), the maximum heart rate was 135 (beats/min), the minimum heart rate was 63 (beats/min).

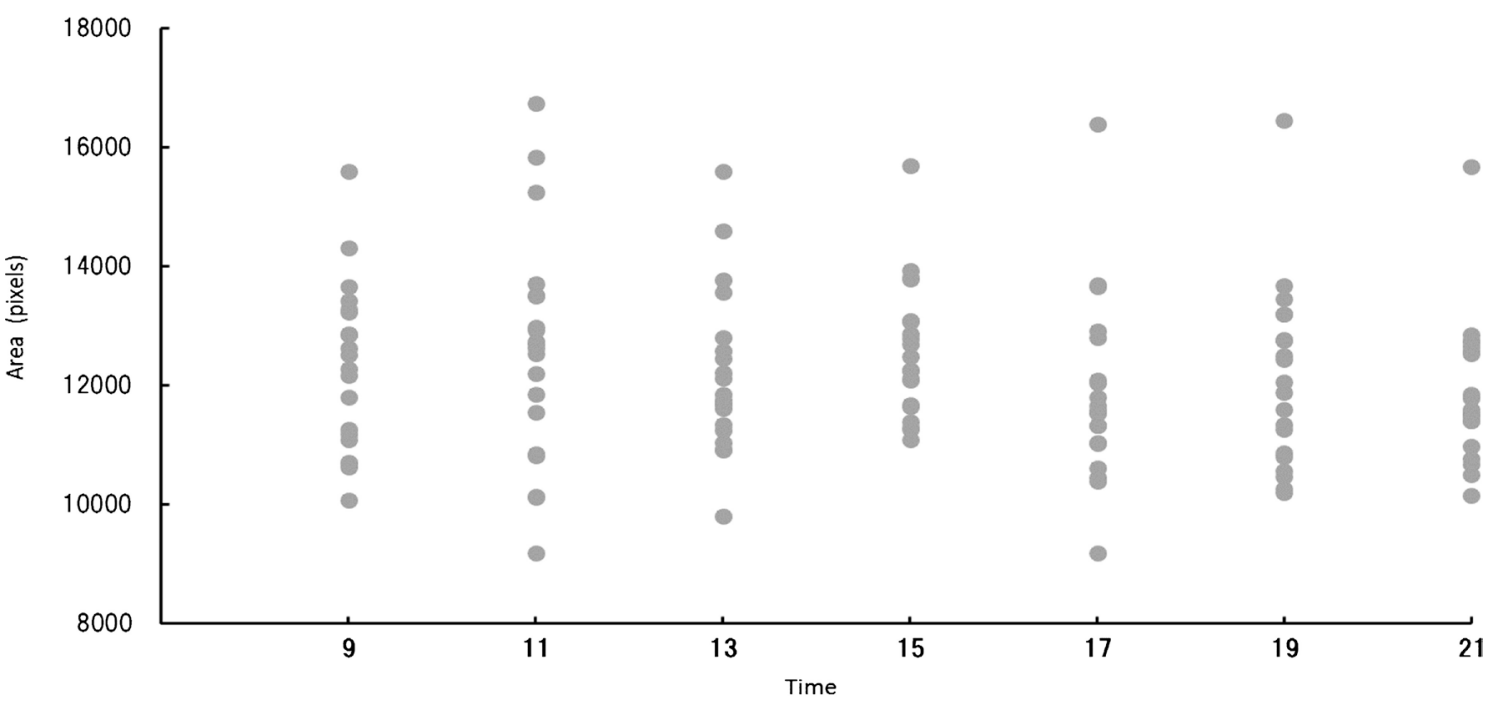

Figure 3. Daily fluctuations of the energy field parameter Area. The average value and standard deviation of the energy field indicator Area at the time of awakening of all subjects from 9:00 to 21:00. 
units at 13:00, 85.2 \pm 5.9 units at 15:00, 84.0 \pm 2.1 units at 17:00, 84.4 \pm 2.2 units at 19:00, and $82.9 \pm 2.1$ units at 21:00 (Figure 4). A significant decrease was observed at 21:00 compared to the starting value at 9:00 $(\mathrm{p}<0.01)$. The intraday fluctuation of intensity also demonstrated trimodality, similar to the area parameter. Thus, the intensity of the evoked photon parameter, which is an energy index, and the diurnal change of the region show rhythmic properties. The energy index intensity revealed fluctuations in in vivo energy during the waking hours. Therefore, various types of fatigue in the awake state can be reflected as significant decreases in the energy field parameters of area and intensity.

\subsection{Fluctuations in the $s$-IgA/Total Protein Ratio}

The s-IgA/total protein ratio was $13.8 \pm 1.3 \%, 15.0 \pm 1.4 \%, 14.1 \pm 1.3 \%, 14.4 \pm$ $1.5 \%, 13.3 \pm 1.5 \%, 14.3 \pm 1.3 \%$, and $12.9 \pm 2.1 \%$ at $9: 00,11: 00,13: 00,15: 00$,

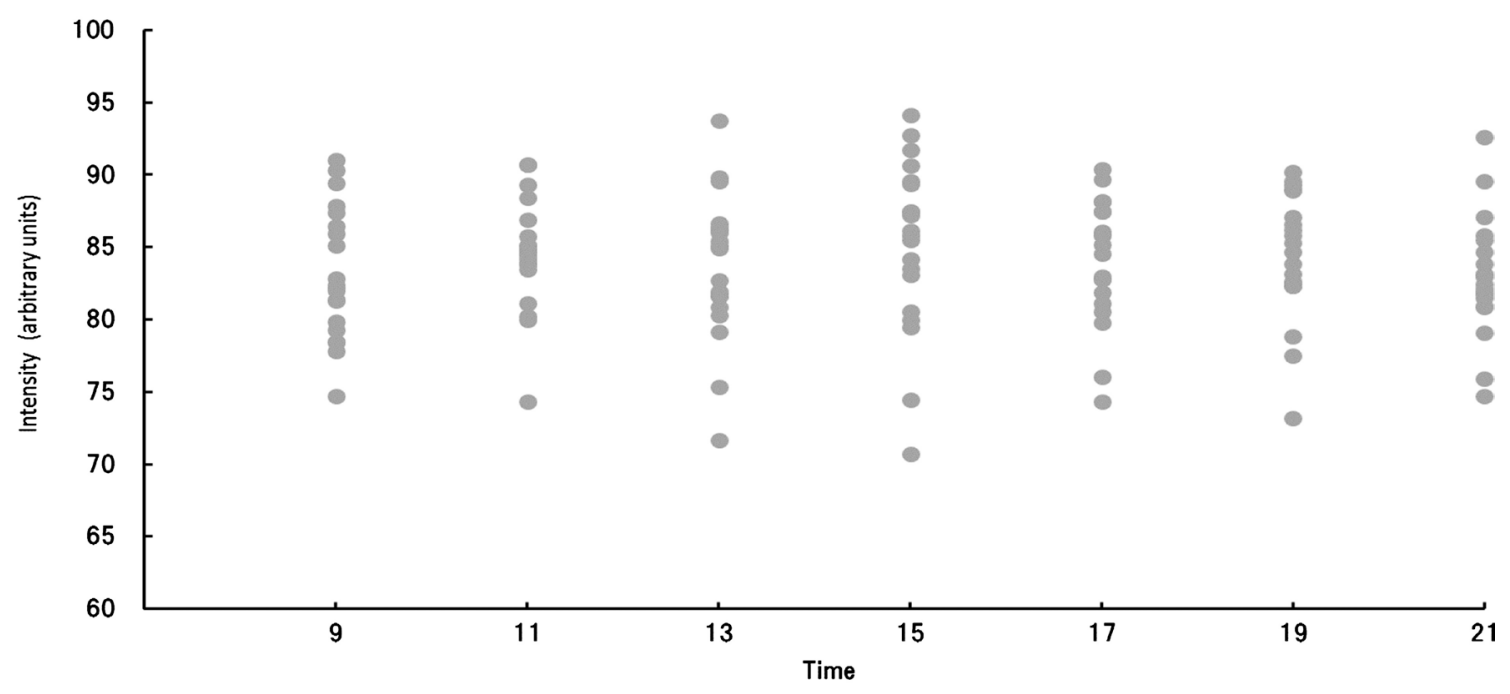

Figure 4. Daily fluctuations of the energy field parameter Intensity. The average value and standard deviation of the energy field index Intensity of all subjects during awakening from 9:00 to 21:00.

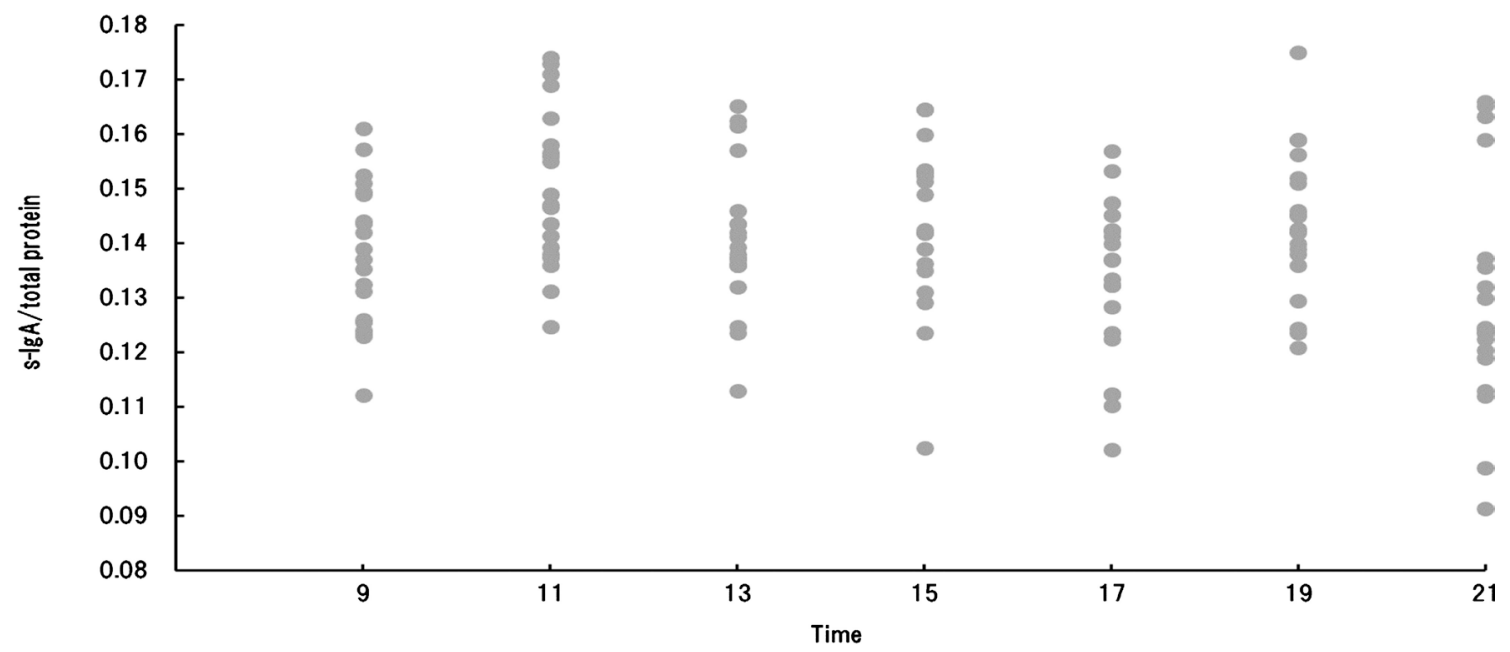

Figure 5. Daily fluctuations of s-IgA/total protein ratio. The average value and standard deviation of the energy field index s-IgA/total protein at the time of awakening of all subjects from 9:00 to 21:00. 
17:00, 19:00, and 21:00, respectively (Figure 5). The rhythmicity matched that of the area and intensity energy indicators of the evoked photon parameter.

The three parameters showed circadian rhythms of almost the same pattern after the subjects awoke, implying that stress parameters are related to these energy parameters related to fatigue. Based on this result, the correlation between the evoked photon energy field parameters and s-IgA from saliva was corroborated.

\subsection{Correlation between the Evoked Photon Energy Field Parameters and s-IgA in the Saliva}

There was a significant correlation between the area energy field index and the s-IgA level $(r=0.84, p<0.05)$. There was also a significant correlation between the intensity energy field index and the s-IgA level $(r=0.78, p<0.05)$.

\section{Discussion}

In this study, we used a GDV device to detect the luminescence phenomena of the evoked photons. This served as an in vivo energy state diagnostic marker.

By examining the energy state in the living body through the evoked photons, we examined how diurnal variations could be captured. In the past, the verification method for investigating daily fluctuations in bioenergy relied on interviews and psychological tests [32] [33] [34] [35]. However, it is difficult to objectively evaluate subjective elements.

Examinations and analyses by electrophysiological or biochemical means require a great deal of time. The evoked photon parameter shows the activity of the cells and the degree of the chemical reaction, and this can be an important index for quantifying living activities.

Examinations using the evoked photon parameter are noninvasive. Thus, it is possible to obtain a large amount of physiological information in a short time with a lower burden on the body. Physiological information is contained in the luminescence intensity and luminescence area of the photons. Thus, measuring the evoked photons can be useful as a preliminary measurement for obtaining biological and general health information.

The results of this study provided verification that rhythmic fluctuations can be observed over a period of $12 \mathrm{~h}$ starting at the time when a person arises. The observed daily fluctuations showed a trimodal diurnal variation. This was reflected in both the area and the intensity of the energy index. Furthermore, the physiochemical s-IgA level measurements from the obtained saliva samples matched the trimodal diurnal variation.

s-IgA is known to reflect the endogenous circadian rhythm [35] [36]. Since the phase relation between s-IgA levels and the area and intensity of the energy field index is aligned, these indices have an internal synchronization relationship. s-IgA is also a chemical indicator of stress. Its levels decrease as the stress level increases, and vice versa. On the other hand, as the stress level increases, 
the production of active oxygen increases. Therefore, there is a high correlation between increases and decreases in the area and intensity to s-IgA levels. Hacker GW et al. found out that there was also a significant correlation between the GDV field index from the first moment of consciousness to the early morning (9:25-12:25) and the biochemical indicators measured from the saliva [16]. Numerous reports have indicated that the salivary immune protein $(\mathrm{s}-\operatorname{Ig} \mathrm{A})$ reflects fatigue levels in daily life, and many relationships between fatigue and active oxygen in the blood have also been reported. Therefore, these indicators are known to have a circadian rhythm.

The daily fluctuation of $s-\operatorname{IgA}$ as an indicator in this verification showed the same trend as in the previous study, and variations during the day were observed. From this fact, a diurnal variation was observed in the fatigue levels of human subjects, and since a phase relationship was recognized as showing a significant correlation with area and intensity, the area of the energy field index can reflect the levels of awakening and the degree of fatigue can be reflected in the numerical value of intensity.

From the above, the energy field indicator by GDV is expected to be a suitable index for quantifying human bioenergy in the fields of health and medicine. According to Konstantin Korotkov, GDV is the electricity that is released externally because of the change in bioenergy and body tension resulting from exercise or therapy, which is considered to be beneficial to the body. Thus, GDV can be used to evaluate the bioenergetics of the body and human health [8].

In addition to conventional methods, we believe that using continuous body function measurement as one index along with this new measurement index can help provide an individualized health evaluation, although more subjects are necessary for convincing the relationship between the conventional methods and the GDV methods. The numerical value captured by the evoked photon parameter reflects a diurnal variation of fatigue stress, providing a new viewpoint for evaluating human health.

\section{Conclusions}

In this study, we investigated diurnal variations in energy fluctuations in human subjects using the evoked photon parameter. This evoked photon results from the weak light emission phenomenon derived mainly from reactive oxygen and free radicals in the living body. We examined the in vivo energy fluctuations during a $12 \mathrm{~h}$ period starting at awakening.

Biological information from the evoked photon parameter could be a useful index. The area and intensity of the energy field index showed a significant correlation with s-IgA levels, and it became clear that there was a synchronized relationship. A significant decrease $(\mathrm{p}<0.01)$ was observed in the average area and intensity of the energy field index after $12 \mathrm{~h}$ from the initial value at awakening. In addition, the mean value of $\mathrm{s}-\mathrm{IgA}$ also showed a significant decrease $(\mathrm{p}<$ 0.05 ) with respect to the initial value. A significant relationship was found in the 
correlation between the area/intensity and s-IgA levels. Thus, the area and intensity of the energy field index reflect fatigue and stress.

The evoked photon parameter, as captured using GDV, enables easy measurement of the diurnal variation in human body energy. We expect that this new viewpoint will be a useful evaluation tool for measuring general health.

\section{Acknowledgements}

This work was supported in part by a Grant-in-Aid for Scientific Research (c) No. 17K01789 from the Japan Society for the Promotion of Science.

\section{Conflicts of Interest}

The authors declare no conflict of interests regarding the publication of this paper.

\section{References}

[1] Foster, G.M. and Anderson, B.G. (1978) Medical Anthoropology, John Wiley \& Sons, Inc.

[2] Mairan, De. (1729) Observation botanique, Histoire de l'Académie royale dessciences avec les mémoires de mathématique et de physique tirés des registres decette Académie, 35.

[3] Richter, C.P. and Wang, G.H. (1926) New Apparatus for Measuring the Spontaneous Motility of Animals. Journal of Laboratory and Clinical Medicine, 12, 289-292.

[4] Kleitman, N. (1939) Sleep and Wakefulness. Chicago: University of Chicago Press.

[5] Moore, R.Y. and Eichler, V.B. (1972) Loss of a Circadian Adrenal Corticosterone Rhythm Following Suprachiasmatic Lesions in the Rat. Brain Research, 42, 201-206. https://doi.org/10.1016/0006-8993(72)90054-6

[6] Stephan, F.K. and Zucker, I. (1972) Circadian Rhythms in Drinking Behavior and Locomotor Activity of Rats Are Eliminated by Hypothalamic Lesions. Proceedings of the National Academy of Sciences of the United States of America, 69, 1583-1586. https://doi.org/10.1073/pnas.69.6.1583

[7] Inaba, F. and Shimizu, Y. (2011) Study on Information about Living System by Biophoton. Tohoku University Press.

[8] Korotkov, K. (2002) Human Energy Field Study with GDV Bioelectrography. Backbone Publishing Co., Fair Lawn.

[9] Dobson, P. and O'Keeffe, E. (2005) The Efficacy of the Gas Discharge Visualisation Technique as a Measure of Physical and Mental Health. Computer-Based Medical Systems, 455-457.

[10] Konstantin, K. and Berney, W. (2004) Assessing Biophysical Energy Transfer Mechanisms in Living Systems: The Basis of Life Processes. Journal of Alternative and Complementary Medicine, 10, 49-57.

[11] Cioca, G., Korotkov, K., Giacomoni, P.U., Rein, G. and Korotkova, K. (2004) Effects of Exposure to Electromagnetic Fields from Computer Monitors on the Corona Discharge from Skin. In: Korotkov, K., Ed., Measuring Energy Fields State of the Science, Backbone, Fair Lawn, 183-192.

[12] Korotkov, K. (2002) GDV in Medicine 2002: Application of the GDV Bioelectrography Technique in Medicine. In: Francomano, C.A., Jonas, W.B. and Chez, R.A., 
Eds., Proceedings: Measuring the Human Energy Field: State of the Science, Samueli Institute, Corona del Mar, 9-22.

[13] Korotkov, K., Donlina, M.Y. and Bascom, R. (2002) Appendix: Translation of Russian Documents Related to GDV. In: Francomano, C.A. and Jonas, W.B., Eds., Proceedings. Measuring the Human Energy Field: State of the Science, Samueli Institute, Corona del Mar, 90-156.

[14] Rizzo-Roberts, N. (2004) GDV Description and Discussion of Safety Issues. In: Korotkov, K., Ed., Measuring Energy Fields. State-of-The-Science, Backbone, Fair Lawn, 23-28.

[15] Augner, C. and Hacker, G.W., Schwarzenbacher, S. and Pauser, G. (2010) Gas Discharge Visualization (GDV). Eine auf physikalischen Methoden und Meridiananalysen basierende Technik zur Untersuchung von Stressreaktionen und energetischen Schwachstellen-Zwischenbericht laufender Forschung. (Gas Discharge Visualization (GDV): A Technique Based on Physical Methods and Meridian Analyses to Detect Stress Reactions and Energetic Weaknesses-Report of Ongoing Research). Deutsche Zeitschrift für Akupunktur, 53, 14-20.

[16] Hacker, G.W., Chr, A. and Pauser, G. (2011) Daytime-Related Rhythmicity of Gas Discharge Visualization (GDV) Parameter Glow Image Area: Time Course and Comparison to Biochemical Parameters Measured in Saliva. In: Buchkapitel, A.E.D. and Korotkov, K., Energy Fields Electrophotonic Analysis in Humans and Naturepp, University Press, Petersburg St., 80-83.

[17] Dobson, P. and O'Keefe, E. (2000) Investigations into Stress and Its Management Using the Gas Discharge Visualization Technique. Journal of Alternative and Complementary Medicine, 12-17.

[18] Bascom, R., Buyantseva, L., Zhegmin, Q., Dolina, M. and Korotkov, K. (2002) Gas Discharge Visualization (GDV)-Bioelectrography. In: Francomano, C.A., Jonas, W.B. and Chez, R.A., Eds., Proceedings. Measuring the Human Energy Field: State of the Science, Samueli Institute, Corona del Mar, 55-66.

[19] Francomano, C.A., Jonas, W.B. and Chez, R.A. (2002) Measuring the Human Energy Field: State of the Science. Samueli Institute, Corona del Mar.

[20] Rizzo-Roberts, N. (2002) Gaseous Discharge Visualization (GDV) Bioelectrography: An Overview. In: Francomano, C.A., Jonas, W.B. and Chez, R.A., Eds., Proceedings. Measuring the Human Energy Field: State of the Science, Samueli Institute, Corona del Mar, 23-30.

[21] Pehek, J.O., Kyler, H.J. and Faust, D.L. (1976) Image Modulation in Corona Discharge Photography. Science, 194, 263-270. https://doi.org/10.1126/science.968480

[22] Giacomoni, P., Hayes, M., Korotkov, K., Krinzhanovsky, E., Matravers, P., Momoh, K.S., et al. (2003) Study of Cultural Aspects of Cosmetology Using the Dynamic Gas Discharge Visualisation Technique. In: Proceedings of the International Congress "Science, Information, Spirit", St. Petersburg, 95.

[23] Vainshelboim, A., Hayes, M., Momoh, K.S. and Konstantin, K. (2004) Observing the Behavioral Response of Human Hair to a Specific External Stimulus Using Dynamic Gas Discharge Visualisation. Journal of Cosmetic Science, 55, S91-S104.

[24] Tokyo Metropolitan University (1989) Physical Education Laboratory: Japanese Physical Fitness Standard Value. 4th Edition, Humaido Co., Tokyo.

[25] Kirlionics Technologies International. http://ktispb.ru/en/news_archive.htm https://translate.google.co.jp/translate?hl=ja\&sl=en\&u=http://ktispb.ru/en/news_ar chive.htm\&prev=search

[26] Akimoto, T., Akama, T., Koda, Y., Waku, T., Hayashi, E., Tatsuno, M., Sugiura, K., 
Amano, K. and Kono, I. (1998) Effects of Repetitious Intense Exercise Training on Resting Salivary IGA. JPFSM, 47, 245-251.

[27] McKechnie, A.A., Wilson, F., Watson, N. and Scott, D. (1988) Anxiety States: A Preliminary Report on the Value of Connective Tissue Massage. Japanese Psychological Research, 27, 125-129.

[28] Nakata, Y., Iijima, S., Maruyama, S., et al. (2000) Levels of Salivary Secretory Immunoglobulin A as a Workload Indicator. Japan Air Self-Defense Force Aeromedical Laboratory Reports, 40, 27-35.

[29] Sakai, K., Yamada, H., Takasu, H., Nakajima, I. and Akasaka, M. (1986) The Study on the Secretory IgA of Human Saliva by the Enzyme Immunoassay. The Japanese Journal of Pediatric Dentistry, 24, 483-484.

[30] Tsubouchi, S., Shirafuji, I., Hamaguchi, M., Matsuura, Y. and Shimizu, N. (1985) Calculating the Energy Expenditure from $\mathrm{HR}-\mathrm{VO}_{2}$ Method. Osaka Research. Journal of Physical Education, 23, 41-45.

[31] Tsubouchi, S., Makoro, S., Hamaguchi, M., Matsuura, Y. and Shimizu, N. (1986) A Study on Estimation of Energy Consumption per Day through Heart Rate. Osaka Research. Journal of Physical Education, 24, 30-33.

[32] Izawa, S., Shirotsuki, K., Sugaya, N., Ogawa, N., Suzuki, K. and Nomura, S. (2007) The Application of Saliva to an Assessment of Stress: Procedures for Collecting and Analyzing Saliva and Characteristics of Salivary Substances. Japanese Journal of Complementary and Alternative Medicine, 4, 91-101. https://doi.org/10.1625/jcam.4.91

[33] Rohleder, N., Nater, U.M., Wolf, J.M., Ehlert, U. and Kirschbaum, C. (2004) Psychosocial Stress-Induced Activation of Salivary Alpha-Amylase. An Indicator of Sympathetic Activity. Annals of the New York Academy of Sciences, 1032, 258-263. https://doi.org/10.1196/annals.1314.033

[34] Rantonen, P.J.F. and Meurman, J.H. (2000) Correlations between Total Protein, Lysozyme, Immunoglobulins, Amylase, and Albumin in Stimulated Whole Saliva during Daytime. Acta Odontologica Scandinavica, 58, 160-165. https://doi.org/10.1080/000163500429154

[35] Deinzer, R., Kleineidam, C., Stiller-Winkler, R., Idel, H. and Bachg, D. (2000) Prolonged Reduction of Salivary Immunoglobulin a (sIgA) after a Major Academic Exam. International Journal of Psychophysiology, 37, 219-232. https://doi.org/10.1016/S0167-8760(99)00112-9

[36] Hucklebridge, F., Clow, A. and Evans, P. (1998) The Relationship between Salivary Secretory Immunoglobulin A and Cortisol: Neuroendocrine Response to Awakening and the Diurnal Cycle. International Journal of Psychophysiology, 31, 69-76. https://doi.org/10.1016/S0167-8760(98)00042-7 